\section{$\underset{\substack{\text { hommes } \\ \text { \& migrations }}}{ }$}

\section{Hommes \& migrations}

Revue française de référence sur les dynamiques

migratoires

$1277 \mid 2009$

France - Allemagne

\title{
L'évolution de la représentation des migrants au cinéma et dans les séries télévisuelles
}

\section{Ceren Türkmen}

Traducteur : Françoise Toraille

\section{(2) OpenEdition}

Journals

\section{Édition électronique}

URL : http://journals.openedition.org/hommesmigrations/175

DOI : 10.4000/hommesmigrations. 175

ISSN : 2262-3353

\section{Éditeur}

Musée national de l'histoire de l'immigration

Édition imprimée

Date de publication : 1 janvier 2009

Pagination : 104-106

ISSN : 1142-852X

\section{Référence électronique}

Ceren Türkmen, "L'évolution de la représentation des migrants au cinéma et dans les séries télévisuelles », Hommes \& migrations [En ligne], 1277 | 2009, mis en ligne le 29 mai 2013, consulté le 01 mai 2019. URL : http://journals.openedition.org/hommesmigrations/175 ; DOI : 10.4000/ hommesmigrations. 175 


\section{L'évolution de la représentation des migrants au cinéma et dans les séries télévisuelles}

Par Ceren Türkmen, université de Munster

La lutte des migrants pour devenir plus visibles et plus présents dans l'espace culturel germanophone semble avoir porté des fruits. C'est tout particulièrement vrai dans la création cinématographique turco-allemande depuis le début des années 1990. Des critiques parlent même d'un nouveau genre cinématographique, le "cinéma du métissage", produit par des migrants de la deuxième et de la troisième génération. Ils sont d'accord pour souligner l'importance de l'impulsion que reçoit ainsi le cinéma allemand. Dans ce cinéma du métissage, des créateurs issus de l'immigration sont désormais eux-mêmes derrière la caméra et nous font partager leur regard.

Les sujets et les styles cinématographiques de ces cinéastes sont tout aussi différents que le sont les créateurs eux-mêmes. Fatih Akin (L'Engrenage, 1998) et Thomas Arslan (Dealer, 1999) marquent le film d'action multiethnique avec des histoires tragiques évoquant des jeunes tombés dans la criminalité urbaine. Ayse Polat (Auslandstournee, 1998) et Kutlig Ataman (Lola und Bilidikid, 1999) mêlent des thèmes et des personnages relevant de la mixité sociale et culturelle. Par exemple, Ataman évoque les difficultés rencontrées par de jeunes travestis d'origine turque dans les milieux prolétaires de grandes métropoles allemandes. Aussi différents soient-ils sur le plan cinématographique, ces premiers films représentatifs du cinéma du métissage montrent un quotidien de la migration méconnu jusqu'alors, puisque considéré du point de vue des migrants, et mettent en lumière leur manque d'ancrage dans la société dominante allemande.

\section{Sortir l'immigré des clichés}

Pour ces jeunes réalisateurs, il convient de critiquer le mode de représentation cinématographique dominant des migrants dans les années 1970. On présentait 
alors les travailleurs immigrés essentiellement comme des victimes incapables de communiquer et de réagir, ce qui est en contradiction avec les grèves ouvrières et les luttes menées en Allemagne contre le racisme par les migrants eux-mêmes. À cette époque, les réalisateurs allemands recouraient souvent à des représentations stéréotypées et indifférenciées et à des clichés. Par exemple, la femme turque et musulmane doublement victime de discrimination dans la société dominante et dans sa propre culture. Ainsi dans Yasemin de Hark Bohms (1988), une jeune femme turque est sauvée par son ami allemand, le héros du film, des brimades qu'elle subit dans son milieu familial. Par ailleurs, à l'écran, les étrangers sont ceux qui commettent des violences ; prisonniers de traditions archaïques, ils mènent en République fédérale une vie résignée, claustrophobe et sans cesse dominée par la crainte de perdre leur propre identité. Il faut préciser que le public auquel ces films s'adressaient était, contrairement à aujourd'hui, en majorité allemand et non issu de l'immigration.

\section{Le multiculti dans les productions actuelles}

Le succès du cinéma du métissage ne s'est pas fait attendre. Fatih Akin, par exemple, s'est vu décerner l'Ours d'or du festival du cinéma de Berlin en 2004 avec Head On, suivi d'autres succès internationaux. Mais, alors qu'au début des années 1990, le cinéma du métissage, tourné vers l'engagement politique et la critique sociale, se situait encore entre films d'auteur et subculture, une nouvelle évolution se dessine peu à peu. Elle se voit surtout dans la production de films et de séries populaires ancrée dans un monde pluriethnique, dans laquelle les différences culturelles et les cultures de la migration sont de plus en plus présentes, et dont les réalisateurs peuvent être allemands. La culture populaire devient un lieu privilégié pour montrer les manipulations, les peurs, les projections du point de vue du multiculturalisme.

Le multiculti est en vogue, c'est indiscutable. Une série de comédies mettant en scène le choc des cultures, comme Téléphone rose de Torsten Wacker ou Mariage à la turque de Stefan Holtz (2005), arrivent sur le marché. De nouvelles séries télévisées, comme Alle lieben Jimmy (Tout le monde aime Jimmy) sur Pro 7 et Türkisch für Anfänger (Turc pour débutants) sur ARD, tentent chacune à leur façon de rendre plus accessible la perception d'une identité turque. Mais la question des stéréotypes sur les migrants reste entière. Des productions récentes laissent à penser qu'on en est peut-être à brader les pratiques culturelles émancipatoires. Dans les séries mentionnées ci-dessus, contrairement à ce qui se passait dans le 
cinéma évoquant les travailleurs étrangers, le recours à l'humour est important, et cela d'autant plus que le regard sur l'autre demeure marqué par des modèles identitaires figés auxquels les comédies multiethniques se réfèrent de manière quasi systématique.

Après trois générations, les fils de migrants continuent à être des migrants, qu'ils aient ou non la citoyenneté allemande. Au mieux, ils oscillent parfois entre deux cultures. Ainsi, les représentations eurocentrées continuent à dominer dans l’idéologie véhiculée par les médias populaires. 